\title{
EVALUATE GERMINATION AND SEEDLING GROWTH OF THREE CULTIVARS OF FENNEL UNDER DIATOMITE AND SOIL MANAGEMENT
}

\author{
M.H. SHAHRAJABIAN ${ }^{1,2,3^{*}}$, M. KHOSHKHARAM ${ }^{1}$, W. SUN $^{2,3}$, Q. CHENG ${ }^{2,3}$ \\ *E-mail: hesamshahrajabian@gmail.com
}

Received: June 20, 2019. Revised: Oct. 16, 2019. Accepted: Oct. 31, 2019. Published online: Dec. 20, 2019

\begin{abstract}
Fennel is a plant belonging to the Apiacea (Umbelliferae) family, and used by humans for a long time for medicinal purposes. In order to evaluate the influence of different materials on germination and seedling growth of three cultivars of fennel, an experiment was conducted in 2018. The cultivars of fennel were Isfahan, Yazd, and Shiraz in main plots, and three materials including $100 \%$ soil, $50 \%$ diatomite $+50 \%$ soil, and $100 \%$ diatomite in subplots, were analyzed in a split plot experiment based on a randomized complete block design (CRBD) with three replications. The highest total germination percentage, coefficient of velocity of germination, epicotile length, fresh epicotile weight and dry epicotile weight was related to Isfahan. The maximum speed of germination, mean germination time, fresh length and dry leaf weight was achieved in Shiraz cultivar. The higher values of total germination percentage, speed of germination and mean
\end{abstract}

germination time were related to $100 \%$ soil, while application of $50 \%$ of soil $+50 \%$ of diatomite had obtained the maximum values of radicle length, epicotile length, fresh epicotile weight, dry leaf weight and dry epicotile weight. The maximum values of coefficient of velocity of germination and fresh leaf weight was achieved in application of $100 \%$ diatomite. It seems that application of $50 \%$ soil $+50 \%$ diatomite and Isfahan and Shiraz cultivars have a great potential of seed germination of seedling growth.

Keywords: mean germination time; fresh epicotiles; germination percentage.

\section{INTRODUCTION}

The aromatic and medicinal plants are important in all over the world (Heidari et al., 2014; Soleymani and Shahrajabian, 2018). Fennel (Foeniculum vulgare Mill.) has

\footnotetext{
1 Dept of Agronomy and Plant Breeding, Isfahan (Khorasgan) Branch, Islamic Azad University, Isfahan, Iran

2 Biotechnology Research Institute, Chinese Academy of Agricultural Sciences, Beijing, China

${ }^{3}$ Nitrogen Fixation Laboratory, Qi Institute, Chuangye, Jiaxing, Zhejiang, China
} 
aromatic, medicinal and flavouring properties, and it is rich in various biological active ingredients (Ozcan and Chalchat, 2010; Soleymani and Shahrajabian, 2012a; Badgujar et al., 2014; Gama et al., 2014). It is cultivated in different parts of the world, such as Europe, the Middle East and Asia (Sadeghpour et al., 2015). In appropriate seed germination is a common phenomenon, which may cause a great concern for crop production, especially medicinal and aromatic crops (Khoshkharam et al., 2010; Ogbaji et al., 2018; Shahrajabian et al., 2018). Seed vigor can be defined as the ability of the seed to germinate and become established under less than optimal conditions, or to survive a series of environmental stresses during germination (Soleymani et al., 2010; Soleymani et al., 2011; Balla et al., 2012; Soleymani et al., 2013).

Diatoms are the most diverse group of phytoplankton ranging in the size from a few micrometers to a few millimetres and exist either as single cells or chains of cells (Aksakal et al., 2013; El-Sherif et al., 2018). Huang et al. (2012) concluded that diatomite is a siliceous sedimentary rock with a porous structure, low density, high surface area and excellent thermal resistance, and it is readily available and environmentally friendly in organic agriculture. El-Sherif et al. (2018) found that diatomite can improve the growth and mitigate the negative effects of salinity stress, and also reduce the negative effects of water stress. Yong et al. (2018) mentioned that favourable temperatures and water supplies are the most important conditions required for germination and seed emergence. Unfortunately, in Iran the available researches and studies on diatomite and application of this technology for medicinal crop cultivation is limited. Therefore, the aim of this research was to evaluate changes of seed germination and seedling growth characteristics of fennel cultivars in centre of Iran to different managements of diatomite application.

\section{MATERIAL AND METHODS}

Diatomite and three varieties of fennel were obtained from Agricultural Research Centre, Isfahan, Iran. The cultivars of fennel were Isfahan, Yazd, and Shiraz in main plots, and three materials, including $100 \%$ soil, $50 \%$ diatomite $+50 \%$ soil, and $100 \%$ diatomite in subplots, were analyzed in a split plot experiment, based on a randomized complete block design (CRBD) with three replications in a greenhouse at Mojgan Agricultural Company, Mahmood Abad, Isfahan, Iran (Latitude $32^{\circ} 52^{\prime} \mathrm{N}$, Longitude $51^{\circ} 34^{\prime} \mathrm{E}$ and $1660 \mathrm{~m}$ elevation) in 2018.

A number of 50 seeds per pots were planted. Germination percentage, germination speed (GR), mean germination time to complete germination (MGT), and coefficient of velocity of germination $(\mathrm{CVG})$ were measured with equations number $1,2,3$ and 4 , respectively. 


\section{EVALUATE GERMINATION AND SEEDLING GROWTH OF THREE CULTIVARS OF FENNEL}

Germination percentage $=$ number of germinated seed $/ 100$

$$
\begin{array}{r}
G R=\Sigma \frac{N}{\Sigma(n \times g) N} \\
M T G=\Sigma \frac{N i D i}{N}
\end{array}
$$

where, $n$ is the number of germinated seed on growth day and $g$ is the number of germination seeds.
$N$ : total seed number, Ni: number of germinated seed per day, and Di: the number of required days for germination.

$$
C V G=\frac{1}{M T G}
$$

Germinated seeds were carried out by using three replicates of 50 seeds and other seeds were cultured to determine dry matter. Radicle and epicotile of germinated seeds were measured for length and weight characteristics. To this purpose, 10 seeds were chosen randomly, within those germinated first. The selected seedlings were oven-dried for $48 \mathrm{hrs}$ at $65^{\circ} \mathrm{C}$ for dry weight measurement. Analysis of variance (ANOVA) was used to evaluate the significant differences. The Multiple Range Test of Duncan performed the separation means $(p<0.05)$. All statistics was performed with the SAS statistical software.

\section{RESULTS AND DISCUSSION}

The influence of cultivar was significant on total germination percentage, speed of germination, radicle length, epicotile length, fresh leaf weight, fresh epicotile weight, dry leaf weight and dry epicotile weight. Except fresh epicotile weight, dry leaf weight and dry epicotile weight, all experimental characteristics namely, total germination percentage, speed of germination, mean germination time, coefficient of velocity germination, radicle length, epicotile length and fresh leaf weight was significantly influenced by material components (Table 1).

The highest total germination percentage $(75.99 \%)$ was belonged to Isfahan cultivar, which had meaningful differences with other cultivars. The total germination percentage in Yazd and Shiraz cultivar was $59.86 \%$ and $63.82 \%$, respectively. The appropriate seed germination is very important for final successful productions of crops (Shahrajabian etal., 2011; Soleymani and Shahrajabian, 2017).

The higher speed of germination was related to Shiraz cultivar, followed by Yazd and Isfahan. Although, there was a significant difference between Isfahan and Shiraz, both of these cultivars had no significant differences with Yazd.

The maximum and the minimum mean germination time was achieved in Shiraz and Isfahan cultivar, respectively. Uniformity and increase percentage of seedling emergence in direct seedling planting significantly 
influence the yield and quality of crops (Khoshkharam et al., 2010; Soleymani and Shahrajabian, 2012b; Soleymani and Shahrajabian, 2012c; Ogbaji et al., 2013; Shahrajabian et al., 2013; Soleymani et al., 2016).

Although, the higher value of coefficient of velocity of germination was obtained for Isfahan cultivar, compare to those of other cultivars, no significant differences were found between treatments.

The higher radicle length was related to Yazd $(2.60 \mathrm{~cm})$, followed by Isfahan $(2.50 \mathrm{~cm})$ and Shiraz $(2.43 \mathrm{~cm})$. On the one hand, Isfahan had significant difference with Shiraz; on the other hand, its difference with Yazd was not significant. The highest and the lowest epicotile length was related to Isfahan $(6.50 \mathrm{~cm})$ and Yazd $(3.66 \mathrm{~cm})$, respectively, which had meaningful differences with other.

The higher fresh leaf weight was related to Shiraz $(0.55 \mathrm{~g})$, followed by Isfahan $(0.51 \mathrm{~g})$ and Yazd $(0.31 \mathrm{~g})$, respectively. Although, there was no significant difference between Isfahan and Shiraz, both of these cultivars had meaningful difference with Yazd.

The maximum and the minimum fresh epicotile weight were belonged to Isfahan and Yazd cultivar, respectively. Fresh epicotile weight in Isfahan, Yazd and Shiraz was $0.60 \mathrm{~g}$, $0.38 \mathrm{~g}$ and $0.47 \mathrm{~g}$, respectively.

The maximum and the minimum dry leaf weight was related to Shiraz and Yazd, respectively, which had meaningful difference with each other. However, no significant difference was found between Isfahan and Shiraz cultivar. The higher dry epicotile weight was achieved in usage of Isfahan, followed by Shiraz and Yazd, respectively. All differences between treatments were significant (Table 1).

The maximum and the minimum total germination percentage and speed of germination were achieved in usage of $100 \%$ soil and $100 \%$ diatomite, respectively, which had meaningful differences with each other. The highest and the lowest mean germination times were related to $100 \%$ soil, and $50 \%$ soil $+50 \%$ diatomite, respectively. All differences between treatments were meaningful.

Application of $100 \%$ soil had obtained the lowest coefficient of velocity of germination and radicle length, which had meaningful differences with other treatments. Delayed and reduced germination and seedling emergence cause nonuniform and establishment; therefore, seedlings are subject to soil-borne pathogens (Nourimand et al., 2011; Shahrajabian and Soleymani, 2017; Shahrajabian et al., 2017; Abdollahi et al., 2018). The higher values of coefficient of velocity of germination and radicle length were observed in $50 \%$ soil $+50 \%$ diatomite and $100 \%$ diatomite, respectively.

The maximum and the minimum epicotile length was related to $50 \%$ soil $+50 \%$ diatomite and $100 \%$ diatomite, respectively. All differences between treatments were meaningful. 
EVALUATE GERMINATION AND SEEDLING GROWTH OF THREE CULTIVARS OF FENNEL

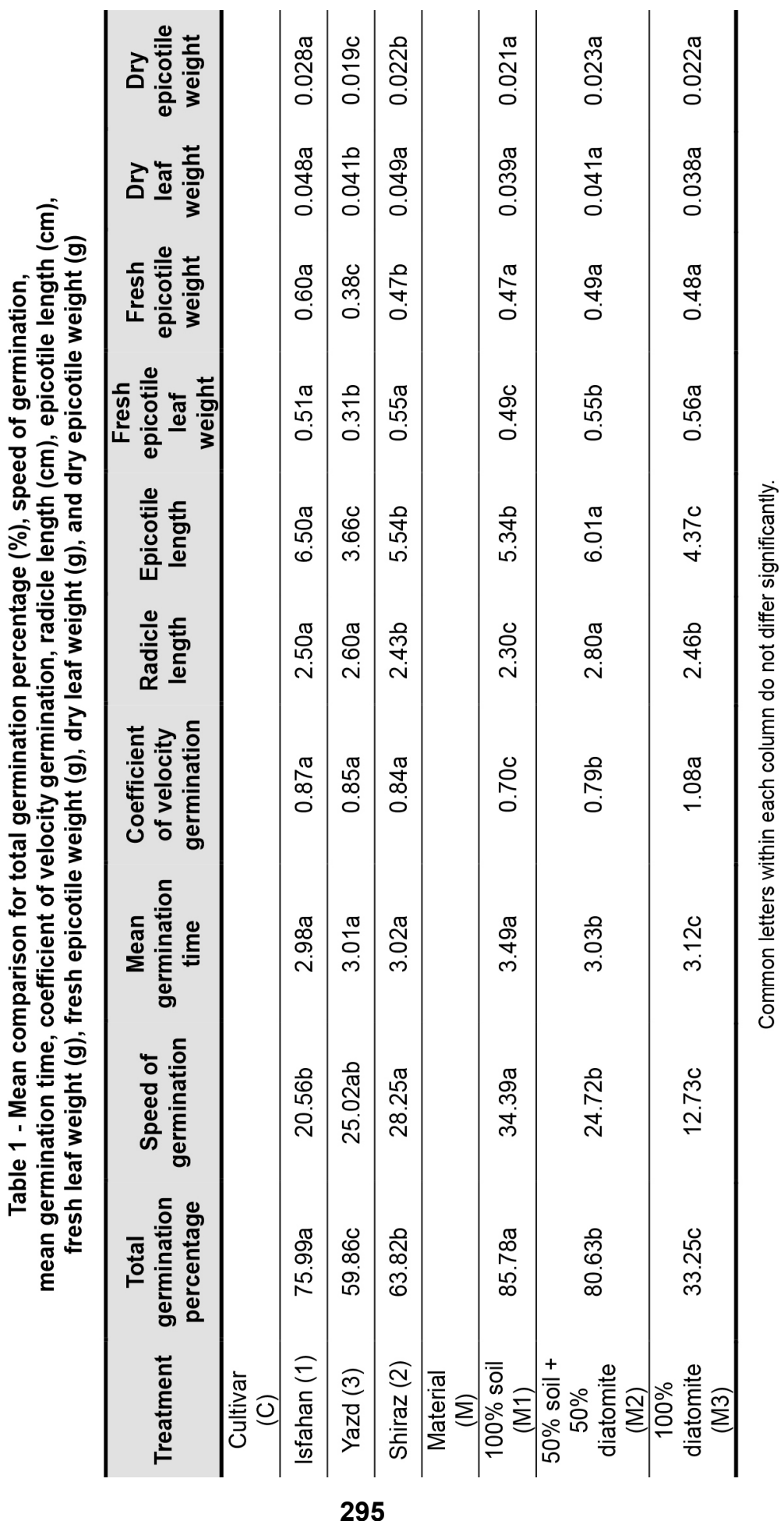


The higher values of fresh leaf weight was related to $100 \%$ diatomite, followed by $50 \%$ soil $+50 \%$ diatomite and $100 \%$ soil, respectively, which had significant differences with each others. Application of $50 \%$ soil $+50 \%$ diatomite had obtained the highest values of fresh epicotile weight, dry leaf weight and dry epicotile weight. There were not any significant differences for fresh epicotile weight, dry leaf weight and dry epicotile weight between treatments. The minimum fresh epicotile weight and dry epicotile weight were achieved in $100 \%$ of application of soil (Table 1).

\section{CONCLUSIONS}

Germination ability and percentage of medicinal crops are of fundamental importance, influencing the viability of the plants developing from the grains. The highest total germination percentage, coefficient of velocity of germination, epicotile length, fresh epicotile weight and dry epicotile weight was related to Isfahan. The maximum speed of germination, mean germination time, fresh length and dry leaf weight was achieved in Shiraz cultivar. The higher values of total germination percentage, speed of germination and mean germination time were related to $100 \%$ soil, while application of $50 \%$ of soil $+50 \%$ of diatomite had obtained the maximum values of radicle length, epicotile length, fresh epicotile weight, dry leaf weight and dry epicotile weight.

The maximum values of coefficient of velocity of germination and fresh leaf weight was achieved in application of $100 \%$ diatomite. All in all, on the basis of results, it can be concluded that application of $50 \%$ soil $+50 \%$ diatomite and Isfahan and Shiraz cultivars have a great potential of seed germination of seedling growth.

\section{REFERENCES}

Abdollahi, M., Soleymani, A. \& Shahrajabian, M.H. (2018). Evaluation of yield and some physiological indices of potato cultivars in relation to chemical, biological and manure fertilizer. Cercet.Agron. in Moldova, 2(174): 53-66, DOI: 10.2478/cerce-20180016

Aksakal, E.L., Angin, I. \& Oztas, T. (2013). Effects of diatomite on soil consistency limits and soil compactibility. Catena, 101: 157163, DOI: 10.1016/j.catena.2012.09. 001

Badgujar, S.B., Patel, V.V. \& Bandivdekar, A.H. (2014). Foeniculum vulgare Mill: a review of its botany, phytochemistry, pharmacology, contemporary application, and toxicology. Biomed Res. Int. Article ID 842674, 32 p., DOI: $10.1155 / 2014 / 842674$

Balla, K., Karsal, I., Bencze, S. \& Veisz, O. (2012). Germination ability and seedling vigour in progeny of heatstressed wheat plants. Acta Agron. Hung., 60(4): 298-308, DOI: 10.15 56/AAgr.60.2012.4.1

El-Sherif, F., El-Zaina, D., \& Yap, Y.-K. (2018). Diatomite improves productivity and quality of Moringa 
oleifera grown in greenhouse. Electronic J.Biol., 14(1): 1-6.

Gama, J.S.N., Neto, A.C.A., Bruno, R.L.A., Junior, L.R.P. \& Medeiros, J.G.F. (2014). Thermotherapy in treating fennel seeds (Foeniculum vulgare Mill.): effects on health and physiological quality. Rev. Ciênc Agron., 45(4): 842-849.

Heidari, Z., Kamkar, B. \& Sinaki, J.M. (2014). Influence of temperature on seed germination response of fennel. Adv. Plants Agric. Res, 1(5): 207-213, DOI:10.15406/apar.2014. 1.00032

Huang, C., Zhang, H., Zhao, Y., Chen, S. \& Liu, Z. (2012). Diatomitesupported $\mathrm{Pd}-\mathrm{M} \quad(\mathrm{M}=\mathrm{Cu}, \mathrm{Co}, \mathrm{Ni})$ bimetal nanocatalysts for selective hydrogenation of long-chain aliphatic esters. J. Colloid Interface Sci., 386(1): 60-65, DOI: 10.1016/j.jcis. 2012.07.032

Khoshkharam, M., Rezaei, A., Soleymani, A. \& Shahrajabian, M.H. (2010). Effects of tillage and residue management on yield components and yield of maize in second cropping after barley. Res. on Crops, 11(3): 659-666.

Nourimand, M., Mohsenzadeh, S., da Silva, J.A.T. \& Saharkhiz, M.J. (2011). Allelopathic potential of fennel (Foeniculum vulgare Mill.). Med.Aromat. Plant Sci.Biotechnol., 5(1): 54-57.

Ogbaji, P.O., Shahrajabian, M.H. \& Xue, $X$. (2013). Changes in germination and primarily growth of three cultivars of tomato under diatomite ad soil materials in auto-irrigation system. Int.J.Biol., 5(3): 80-84, DOI:10.5539/ijb.v5n3p80

Ogbaji, P.O., Li, J., Xue, X., Shahrajabian, M.H. \& Egrinya, E.A. (2018). Impact of bio-fertilizer or nutrient on spinach (Spinacea oleracea) growth and yield in some province soils of P.R. China. Cercet.Agron. in Moldova, 2(174): 43-52, DOI: $10.2478 /$ cerce-2018-00 15
Özcan, M.M. \& Chalchat, J.C. (2010). Comparison of chemical composition of essential oil obtained from different parts of Foeniculum vulgare ssp. piperitum used as condiment. J.Food Biochem., 34(6): 1268-1274, DOI: $10.1111 / \mathrm{j} .1745-4514.2010 .003$ 70.x

Sadeghpour, N., Khaki, A.A., Najafpour, A., Dolatkhah, H. \& Montaseri, A. (2015). Study of Foeniculum vulgare (fennel) seed extract effects on serum level of estrogen, progesterone and prolactive in mouse. Crescent J.Med.Biol.Sci., 2(1): 23-27.

Shahrajabian, M.H., Soleymani, A. \& Naranjani, L. (2011). Grain yield and forage characteristics of forage sorghum under different plant densities and nitrogen levels in second cropping after barley in Isfahan, Iran. Res. on Crops, 12(1): 68-78.

Shahrajabian, M.H., Xue, X., Soleymani, A., Ogbaji, P.O. \& Hu, Y. (2013). Evaluation of physiological indices of winter wheat under different irrigation treatments using weighing lysimeter. Intl.J.Farm.Alli.Sci., 2(24): 1192-1197.

Shahrajabian, M.H. \& Soleymani, A. (2017). Responses of physiological indices of forage sorghum under different plant populations in various nitrogen fertilizer treatments. IJPSS, 15(2): 1-8.

Shahrajabian, M.H., Soleymani, A., Ogbaji, P.O. \& Xue, X. (2017). Survey on qualitative and quantitative traits of winter wheat under different irrigation treatments using weighing lysimeter in north China plain. IJPSS, 15(4): 1-11.

Shahrajabian, M.H., Wenli, S. \& Qi, C. (2018). A review of goji berry (Lycium barbarum) in traditional Chinese medicine as a promising organic superfood and superfruit in modern industry. AJMP, 6(12): 437445, DOI: 10.15413/ajmp.2018.0186 
Soleymani, A., Shahri, M.M., Shahrajabian, M.H. \& Naranjani, L. (2010). Responses of cultivars of canola to sulphur fertilizer and plant densities under climatic condition of Gorgan region, Iran. JFAE, 8(3/4 part 1): 298-304.

Soleymani, A., Shahrajabian, M.H. \& Naranji, L. (2011). The effect of plant density and nitrogen fertilization on yield, yield components and grain protein of grain sorghum. JFAE, 9(3\&4): 244-246.

Soleymani, A. \& Shahrajabian, M.H. (2012a). Response of different cultivars of fennel (Foeniculum vulgare) to irrigation and planting dates in Isfahan, Iran. Res. on Crops, 13(2): 656-660.

Soleymani, A. \& Shahrajabian, M.H. (2012b). Effects of different levels of nitrogen on yield and nitrate content of four spring onion genotypes. IJACS, 4(4): 179-182.

Soleymani, A. \& Shahrajabian, M.H. (2012c). The effects of $\mathrm{Fe}, \mathrm{Mn}$ and $\mathrm{Zn}$ foliar application on yield, ash and protein percentage of forage sorghum in climatic condition of Esfahan. Int.J.Biol., 4(3): 92-96.

Soleymani, A., Shahrajabian, M.H. \& Naranjani, L. (2013). Effect of planting dates and different levels of nitrogen on seed yield and yield components of nuts sunflower
(Helianthus annuus L.). Afr. J. Agric. Res., 8(46): 5802-5805.

Soleymani, A., Shahrajabian, M.H. \& Khoshkharam, M. (2016). The impact of barley residue management and tillage on forage maize. Rom.Agric.Res., 33: 161167.

Soleymani, A. \& Shahrajabian, M.H. (2017). Assessment of ET-HS model for estimating crop water demand and its effects on yield and yield components of barley and wheat in semi-arid region of Iran. Cercet.Agron. in Moldova, 4(172): 37-49, DOI: 10.1515/cerce-20170034

Soleymani, A. \& Shahrajabian, M.H. (2018). Changes in germination and seedling growth of different cultivars of cumin to drought stress. Cecet.Agron. in Moldova, 1(173): 91-100, DOI: 10.2478/cerce-20180008

Yong, Y., Hu, Y.-G., Shahrajabian, M.H., Ren, C.-Z., Guo, L.-C., Wang, C.-L. \& Zeng, Z.-H. (2018). Changes in dry matter, protein percentage and organic matter of soybean-oat and groundnut-oat intercropping in different growth stages in Jilin province, China. Acta.Agric.Slov., 111(1): 1-7, DOI: 10.14720/aas. 2018.111.1.04 